Available online on 15.08.2020 at http://jddtonline.info
Open Access to Pharmaceutical and Medical Research
unrestricted non-commercial use, provided the original work is properly cited

Open $\odot$ Access

Research Article

\title{
Toxicity of mercury on the brain: ability of extract of Pistacia atlantica regulated effect
}

\author{
Benahmed Fatiha*1, 2, Belhouari Hayet Fatima Zohra², Bounoura Radjaa1, Mehrab Elazhari 2, \\ Kharoubi Omar 1 \\ ${ }^{1}$ Laboratory of Experimental Biotoxicology, Department of Biology, Faculty of Life and Natural Sciences, University of Oran1, Ahmed Ben \\ Bella, 1524 EL M Naouer 31000 Oran, Algeria \\ 2 Department of Biology, University Echahid Ahmed Zabana, Relizane 48000, Algeria
}

\begin{abstract}
Objective: The purpose of this study was to evaluate the neuroprotective effect of $150 \mathrm{mg} / \mathrm{kg}$ extract of the plant Pistacia atlantica against mercury-induced oxidative stress

Methods: Hg was administered intraperitoneally $(2,5 \mathrm{mg} / \mathrm{kg}$ body weight, one time a week), and $P$. atlantica and were given orally by gavage at a daily dose $(150 \mathrm{mg} / \mathrm{kg}$ body weight) to rats for 32 days. 24 male adult Albinos Wistar rats were divided into four groups: group 1 Control, group $2\left(\mathrm{HgCl}_{2}\right)$ group $3(\mathrm{Hg}+P$. atlantica) and group $4(P$. atlantica). Paramatrical tests of oxidative stress and histological sections of the

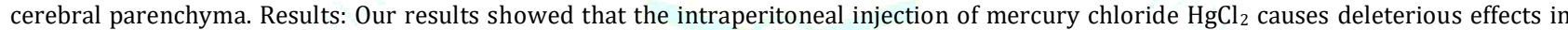
the brain resulting in: a failure of redox status by disrupting the antioxidant defense system by a significant decrease in the activity of catalase glutathione peroxidase, glutathione-s-transferase and superoxide dismutase acetylcholinesterase and increase of the activity of the enzyme lactate dehydrogenase. The levels of lipid peroxidation markers were high in TBARS intoxicated rats with protein oxidation increased in the brain intoxicated by. The continuous use of mercury is also at the origin, in brain tissue However, supplementation of $P$. atlantica extract with mercury-treated rats attenuated some of the harmful and toxic effects of this metal. This clearly demonstrates the protective roles of this plant
\end{abstract}

Keywords: mercury, Pistacia atlantica, Wistar rat, brain, antioxidant, neurotoxicity.

Article Info: Received 09 June 2020; Review Completed 11 July 2020; $\quad$ Accepted 17 July $2020 ; \quad$ Available online 15 August 2020

Cite this article as:

Benahmed F, Belhouari HFZ, Bounoura R, Mehrab E, Kharoubi 0, Toxicity of mercury on the brain: ability of extract of Pistacia atlantica regulated effect, Journal of Drug Delivery and Therapeutics. 2020; 10(4-s):17-24

http://dx.doi.org/10.22270/jddt.v10i4-s.4269

ㅁ.1 *Address for Correspondence:

Benahmed Fatiha, Laboratory of Experimental Biotoxicology, Department of Biology, Faculty of Life and Natural Sciences, University of Oran1, Ahmed Ben Bella, 1524 EL M Naouer 31000 Oran, Algeria

\section{INTRODUCTION}

Mercury is a highly toxic, redox-active element which represents one of the main agents responsible for environmental pollution ${ }^{1}$. Mercury was recorded as the third most dangerous heavy metal after arsenic and lead, according to the Agency for Toxic Substance and Disease Registry Agency (ATSDR)2. It can be found in three different chemical forms; elemental mercury (Hg0), organic mercury (mainly methylmercury), and inorganic mercury (mainly mercuric chloride) ${ }^{2}$. The mercurial exposure is a reality faced by several people around the world 3 , due the routes of exposure to the metal be associated with the used in pharmaceuticals products ${ }^{4}$, use of cosmetics ${ }^{5}$, Mercury is used in various chemical industries. In chlorine production plants, it is widely used for the synthesis of chlorinated compounds and also used in the production of sodium hydroxide. Mercury has various applications including to control weeds, fungi, bacteria and insects ${ }^{6}$.

Mercury adversely affects the cellular, pulmonary, haematological, cardiovascular, immunological, neurological and endocrine systems ${ }^{7}$. The central nervous system, kidney, liver and gastrointestinal system are the main target sites of mercury toxicity8. In addition, symptoms such as headache, impaired coordination, tremor, diarrhea, abdominal cramps, dermatitis, proteinuria, polyneuropathy and hepatic dysfunction occur as a result of mercury toxicity ${ }^{2}$.

The toxicity of mercury can be stopped by using an antioxidant defense mechanism including reducing or eliminating active oxygen species, free radicals, and heavy metals 9 . 
The herbal medicines are widely used in traditional methods to treat various diseases. Specifically, in recent years, the therapeutic and antioxidant effects of some herbal drugs are taken into account for clinical settings $\mathbf{1 0}$. The genus Pistacia (Anacardiaceae) comprising more than 11 species is widely distributed from south-west Asia to north-west Africa. Pistacia atlantica is one of the most widely distributed wild species, which is called "Butom" in Algeria, and is the most characteristic plant species of the arid and semi-arid regions of the country11. it is a highaltitude tree with a height of 2-7 m. The plant has been naturally spread to the Canary Islands, Mediterranean countries, Syria, the Caucasus, Iran, Afghanistan and Pakistan12. This medicinal plant has been used since Pistacia ancient times for treatment of gastrointestinal, liver, and kidney diseases. Various biological effects are reported for species, including antioxidant, antimutagenic, antiatherogenic, anthelmintic, antimicrobial, antiviral, anti-inflammatory, antinociceptive, antitumor, and especially antidiabetic properties ${ }^{13}$.In our present study, we evaluated the protective effect of the leaves aqueous extract of $P$. atlantica against mercuric chloride-induced neurotoxicity in rats by assessing some.

\section{MATERIALS AND METHODS}

\subsection{Plant Material and Preparation of Aqueous Extract}

Leaves of $P$. atlantica Desf used in this study were collected from Oran (Algeria) in October 2018. The plant material was authenticated in the botanic laboratory, University of Oran1. After the leaves were cleaned and airdried, they ground to a fine powder and extracted with distilled water $(1: 10, \mathrm{w} / \mathrm{v})$ under the heat conditions (60 ${ }^{\circ} \mathrm{C}$ ) during $60 \mathrm{~min}$. The mixture was filtered. The obtained decoction was frozen and then lyophilized (freeze-dryer christalpha 2-4 lsc d 37520, Germany).

\subsection{Animals and experimental design}

For our study, a total of 24 rats $(55 \pm 10) \mathrm{g}$ the protocol processes using laboratory animals were in accordance with the Guide for the Care and Use of Laboratory Animals (8th Edition, 2011) and approved by the University's Scientific Committee. Wistar strain rats were randomized to a treatment regimen using Mercury Chloride at 2.5 $\mathrm{mg} / \mathrm{kg}$ body weight (bw), per $125 \mathrm{mg} / \mathrm{Kg}$ with the plant extract for a total duration of 04 weeks or 32 days, the animals were then divided into groups that met the following criteria:

* Group 1: Control group (Control1) consisting of 6 rats receiving daily drinking water by gavage and intraperitoneal injection of $0.9 \% \mathrm{NaCl} 3$ times per week for 4 weeks, i.e., 32 days. 2 Group 2: Intoxicated group $\left(\mathrm{HgCl}_{2}\right)$ treated with Mercury Chloride $2.5 \mathrm{mg} / \mathrm{kg}$ bw administered once per week by intraperitoneal injection for 4 weeks; the number of subjects was also of the order of 6 rats. Group 3: Group intoxicated with Mercury Chloride $2.5 \mathrm{mg} / \mathrm{kg}$ bw injected into the peritoneum once a week, treated with the plant $150 \mathrm{mg} / \mathrm{Kg}\left(\mathrm{HgCl}_{2}+P\right.$. atlantica $)$ administered by daily gavage to 6 animals over a period of 32 days and Groupe 4 treated with the P. atlantica $150 \mathrm{mg} / \mathrm{Kg}$

\subsection{Tissue simple preparation}

At the end of each treatment period the groups of rats are sacrificed by intraperitoneal injection of a $10 \%$ chloral solution (Penthobarbital) at a rate of $3 \mathrm{~mL} / \mathrm{kg}$ body weight (b.w.) The animals were weighed before sacrifice, once sacrificed, the cranial cavity is opened. The brain was freed of adipose tissue, rinsed with a fresh $0.9 \% \mathrm{NaCl}$ solution, weighed and then stored in the freezer at $-80^{\circ} \mathrm{C}$ (CHRIST
ALPHA 2-4 LSC D-37520 ALS Angelantoni Life sciences) for the determination of oxidative stress parameters; part of these organs was fixed in $37 \%$ formalin diluted 1/10th to make histological sections.

\subsubsection{Preparation of tissue homogenates:}

The brains of the different groups studied were used. After grinding and homogenizing the tissue $(0.5 \mathrm{~g})$ in a phosphate buffer (PBS $0.1 \mathrm{~mol} / \mathrm{l}, \mathrm{pH}=7.4$ ) to which 0.3 $\mathrm{mol} / \mathrm{l}$ sucrose and $0.08 \mathrm{~mol} / \mathrm{l}$ potassium chloride $(\mathrm{KCl})$ $(5 \mathrm{ml})$ were added using a WiseTis® homogenizer (HG$15 \mathrm{~A})$ while maintaining a temperature of $4^{\circ} \mathrm{C}$, the homogenate obtained is centrifuged at $7600 \mathrm{rpm}$ for $10 \mathrm{mn}$ at $4^{\circ} \mathrm{C}$, once the supernatant is recovered, it is in turn centrifuged at $12000 \mathrm{rpm}$ for $10 \mathrm{mn}$ to remove cellular debris. Then, aliquots of the supernatant obtained are collected in Eppendorf tubes and stored at $-80^{\circ} \mathrm{C}$ while waiting to determine the oxidative stress parameters.

\subsubsection{Measurement of lipid peroxidation (LPO), Glutathione reduced GSH and antioxidant enzyme activity}

2.3.2.1. Lipid peroxidation (LPO) levels, reduced GSH and antioxidant enzyme activities

2.3.2.2. LPO levels [thiobarbituric acid reactive substances (TBARS)]

Lipid peroxidation was assessed by TBARS assay using the Ohkawa et al.14method. MDA is one of the end products formed during the decomposition of polyunsaturated fatty acids (PUFA) meditated by free radicals. The level of lipid peroxidation was evaluated with the TBARS (Thiobarbituric reactive species) test.

\subsubsection{Reduced GSH levels}

Reduced GSH was determined using a colorimetric technique as described by Sedlak and Lindsay15. The high solubility of the tris buffer provides a favourable medium for the GSH reaction to proceed which reduces the DTNB (also called Ellman's reagent) by producing the yellow chromophore TNB (2-nitro-5 thiobenzoic acid), which has a maximum absorbance at $412 \mathrm{~nm}$, and an oxidized glutathione-TNB adduct (GS-TNB). The rate of formation of TNB, is proportional to the concentration of GSH in the sample. In brief, $1 \mathrm{~mL}$ of cerebrum supernatant (homogenate) is prepared after treatment with $1 \mathrm{~mL}$ of $50 \%$ trichloroacetic acid-distilled water (1:4), and the supernatant obtained after centrifugation at $2400 \mathrm{r} / \mathrm{min}$ for $15 \mathrm{~min}$ was mixed with $0.02 \mathrm{~mL}$ of $0.01 \mathrm{mmol} / \mathrm{L}$ DTNB and an amount of Tris buffer $(0.4 \mathrm{~mol} / \mathrm{L}, \mathrm{pH} 8.5)$. Total GSH content was expressed as nanomoles of GSH per milligram of protein.

\subsection{Effect of treatment on antioxidant enzymes activities} in brain

\subsubsection{Determination of CAT (EC 1.11.16) levels}

CAT was assayed by the method of Aebi16, $250 \mu \mathrm{L}$ of cerebrum homogenates and $250 \mu \mathrm{L}$ of $0.03 \mathrm{~mol} / \mathrm{L} \mathrm{H}_{2} \mathrm{O}_{2}$ (prepared in phosphate buffer, $0.066 \mathrm{~mol} / \mathrm{L}, \mathrm{pH} 7.0$ ) were added in a cuvette. After incubation for 5 min, TiOSO4 was added to the mixture and absorbance was directly measured against phosphate buffer as a blank $420 \mathrm{~nm}$, and one unit of CAT is equal to $1 \mathrm{mmol} \mathrm{H}_{2} \mathrm{O}_{2}$ degraded/ mg of protein.

\subsubsection{Activity of GPX (EC 1.11.1.9)}

GPx activity in brain tissues was assessed by the method of Rotruck et al.17. Glutathione peroxidase (GPX) present in the homogenate catalysis the reduction of a hydrogen 
peroxide (H2O2) by oxidising reduced glutathione (GSH) added at known concentration to form glutathione disulphide (GSSG). The reaction is stopped at a fixed time (t) by addition of TCA the strong acid causing denaturation and aggregation of the GPx and the thiol group (R-SH) of the remaining GSH cysteine is detected by the Ellman reagent giving the chromogenic product TNB which is measured at a wavelength of $340 \mathrm{~nm}$ allowing determination of the peroxidase activity. Briefly the reaction mixture contained $0.2 \mathrm{~mL}$ of Tris- $\mathrm{HCl}$ buffer $(0.4$ $\mathrm{mol} / \mathrm{L}, \mathrm{pH} 7.0), 0.2 \mathrm{~mL}$ of reduced GSH ( $1 \mathrm{mmol} / \mathrm{L}), 0.1 \mathrm{~mL}$ of sodium azide

\subsubsection{Superoxide dismutase (EC 1.15.1.1)}

The assay technique of the Marklund and Marklund $\mathbf{1 8}$ is performed in a buffer (Tris Hcl 50mM and EDTA $10 \mathrm{mM}$ ) at $\mathrm{pH}$ 8.2, with a cerebrum homogenate fraction and pyrogallol $(15 \mathrm{mM})$ and the change in absorbance is monitored for three minutes at a wavelength of $440 \mathrm{~nm}$. Results are expressed in U of SOD / mg protein.

\subsubsection{Determination of lactate dehydrogenase $(L D H)$}

We used kits (Biolabo, French). The decrease in absorbance due to the conversion of NADH to NAD+ in the presence of pyruvate is directly proportional to the LDH activity in the brain homogenate, absorbance is measured at $340 \mathrm{~nm}$.

\subsubsection{Estimation of tissue AChE}

AChE The method for the determination of acetylcholinesterase (AChE) according to the method Ellman's et al.19 consists of providing the enzyme with a substrate acetylthiocholine, the hydrolysis of which by acetycholinesterase in the homogenate releases acetic acid and thiocholine, the latter having an SH thiol group capable of easily cleaving the DTNB which gives the yellow TNB absorbed at $410 \mathrm{~nm}$.

\subsubsection{Determination of total tissue protein contents}

The determination of total protein at the brain tissue level was performed using the method of Lowry et al.20. using bovine serum albumin as a standard, and necessary dilutions were realized to get the correct concentrations of the proteins present in tissues.

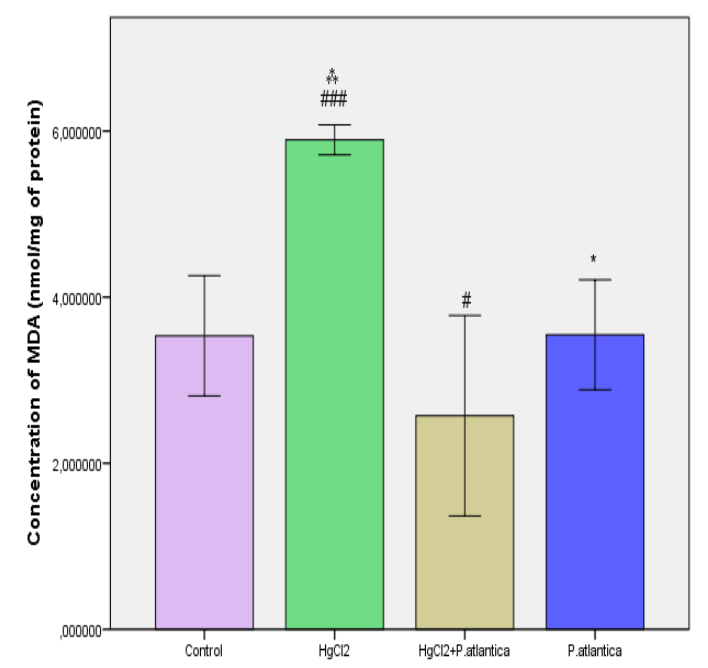

\subsection{Histopathological studies [haematoxylin and eosin (H\&E) staining]}

Samples (brain) from each group were selected, transversely cut and fixed in $10 \%$ buffered formaldehyde solution, then conserved in paraffin. Four micrometre tissue sections were realized and dried at adequate temperature to get Paraffin removed from the glass slides. The next step was to rehydrate sections then stain them with haematoxylin and eosin as nuclear and cytoplasmic stains. The sections were analyzed using Leica®DM5000B microscope and photographed with Leica EC3 digital camera

\section{STATISTICAL ANALYSIS}

The results were represented as mean values \pm standard error (Means \pm ES). Data were analyzed by SPSS (Statistical Packages for Social Science, version 23.0, IBM Corporation, New York, USA) using one-way analysis of variance (ANOVA) followed by Least Significant Difference test (LSD) with $\alpha=0.05$, for comparison of various treatments. A student's t-test was used to determine the significant difference among two different.

\section{RESULTS}

\subsection{Effect of treatment on lipid peroxidation and GSH contents in cerebrum}

Changes in TBARS and GSH levels were illustrated in Figures 1, and a significant increase in TBARS levels by $\mathbf{+ 6 6 . 8 5 \%}$ in cerebrum of intoxicated rats was noted when compared to controls. A highly significant ( $\mathrm{P}<0.001)$ increase was also noted in cerebellum of exposed rats, and these results were accompanied by a reduction in GSH levels in cerebrum of $\mathrm{Hg}$ treated rats $(-\mathbf{3 2 . 4 3 \%})$ in comparison with those of controls. The co-administration of $P$. atlantica and $\mathrm{HgCl}_{2}$ decreased the TBARS production by a rate of $\mathbf{- 5 6 . 3 6} \%$. This treatment alleviated significantly GSH levels in brain regions (+167.46\%) when compared to intoxicated rats. The plant extract showed more efficient results in term of restoring normal values of some altered parameters than the chelation strategy did.

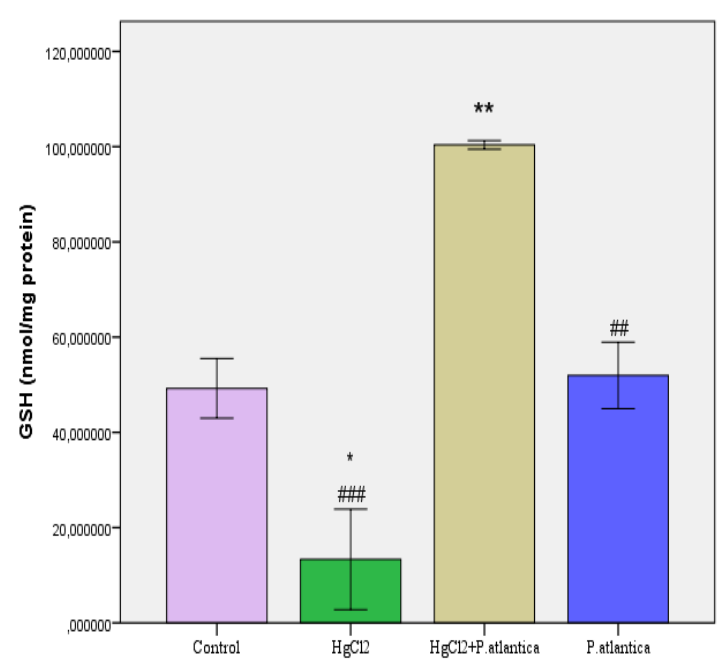

Figure 1: Effects of $P$. atlantica on TBARS level (nmol/mg of proteins) and GSH (nmol /mg proteins) level. The results are represented by the mean \pm standard deviation (Means \pm SD). $\mathrm{P}<0.001($ 粦) $=$ indicates a significant difference in the poisoned rats compared to controls. (\#\#\#) = indicates a significant difference in mercury-poisoned rats treated with the aqueous extract of $P$. at compared to mercury-poisoned rats. $(\#)=$ indicates a significant difference in the poisoned rats treated with the aqueous extract of $P$. at compared to the control rats $\mathrm{p}<0,01$ 
4.2. Effect of treatment on antioxidant enzymes activities in cerebrum

Exposure to $\mathrm{HgCl}_{2}$ produced significant changes in the cerebrum redox status. A very significant decrease $(\mathrm{P}<$ 0.01) in CAT, GPx, GST and SOD activity, activities was
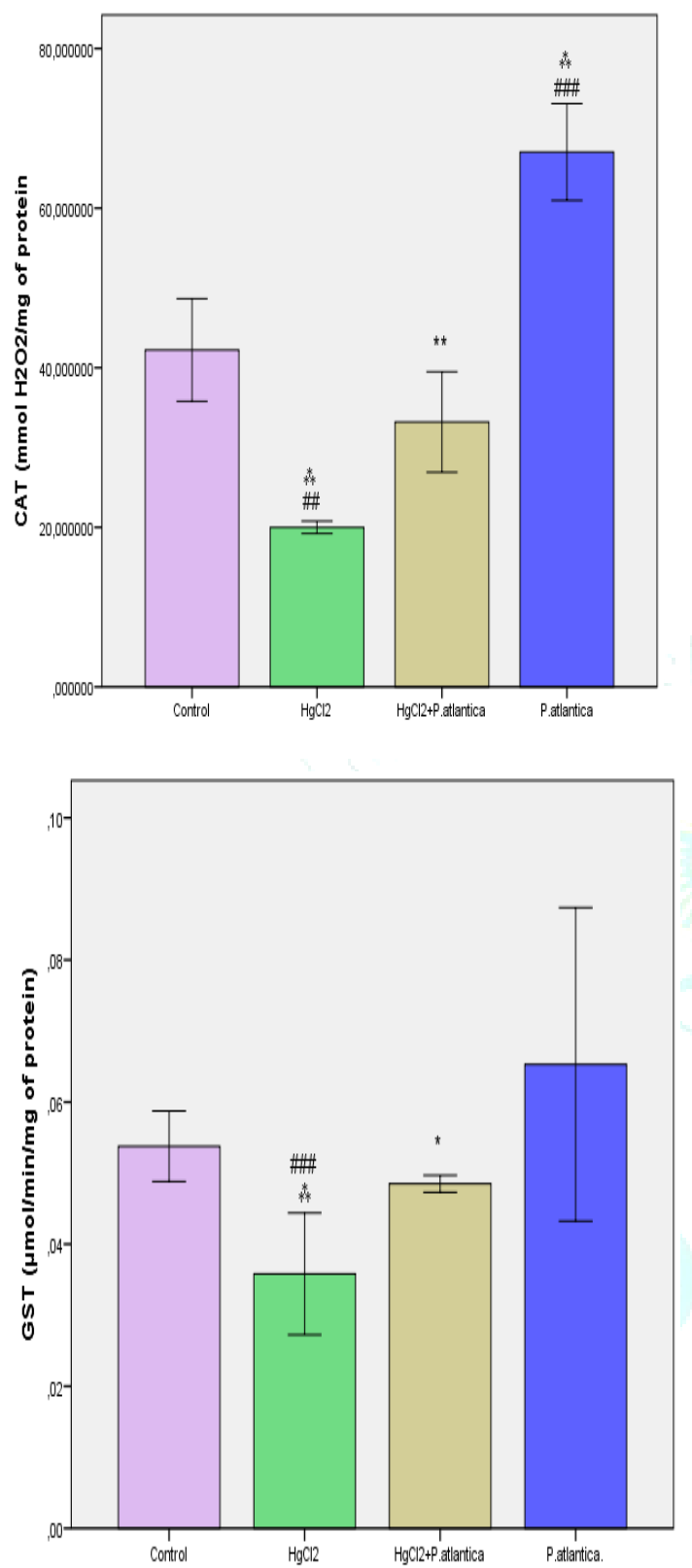

recorded in intoxicated group compared to controls (Figures 2). Oral administration of aqueous $P$. atlantica extract during mercury exposure showed an amelioration in CAT, GPx, GSt, and SOD, by significantly increasing their values $(65.98 \%, 100.35 \%, 100.48 \%$ and $85.71 \%)$ respectively.
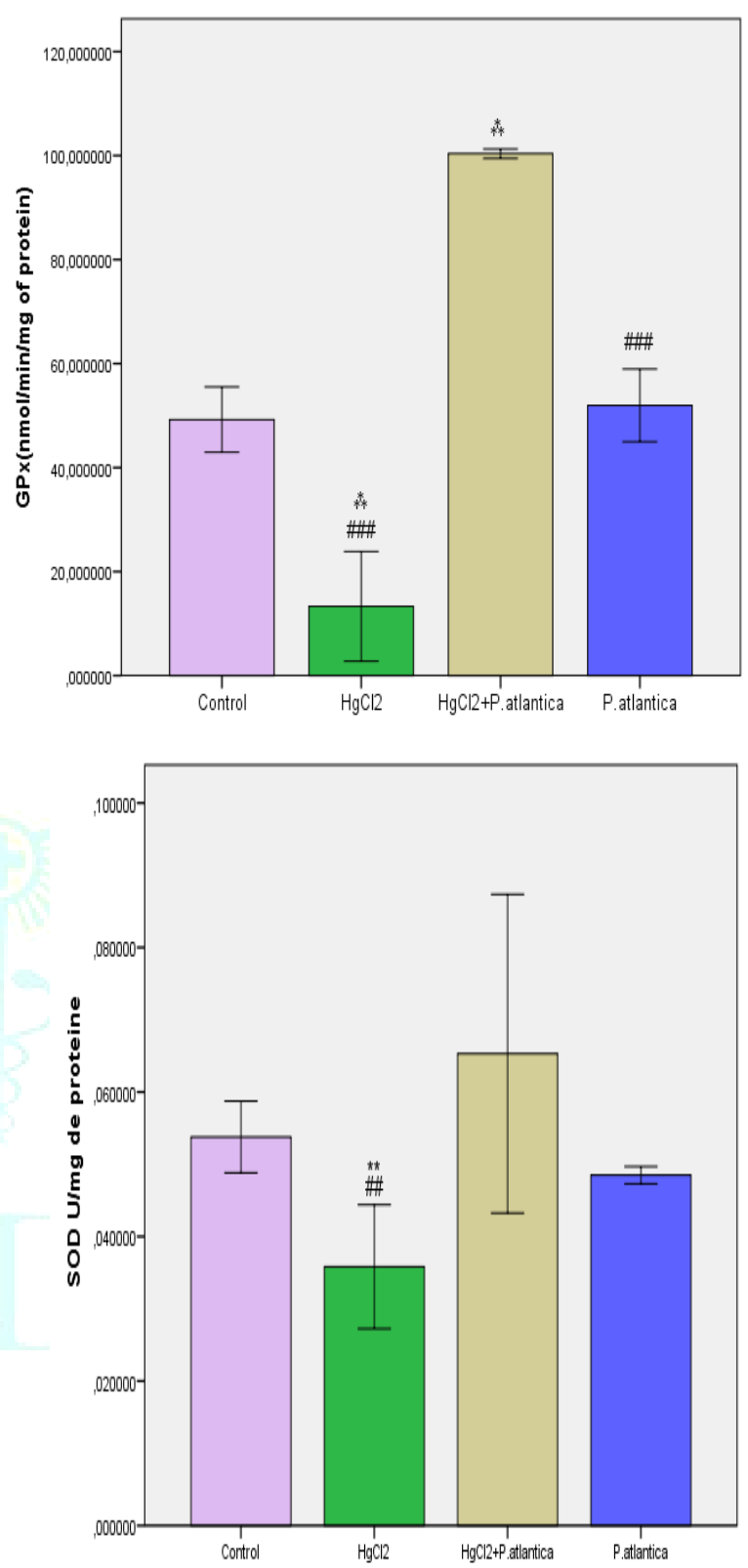

Figure 2: Effects of $P$. atlantica on CAT activity (mmol $\mathrm{H}_{2} \mathrm{O}_{2} / \mathrm{mg}$ of protein), GPx activity (nmol /mn/mg proteins), GST activity ( $\mu \mathrm{mol} / \mathrm{mn} / \mathrm{mg}$ proteins) SOD activity $(\mathrm{U} / \mathrm{mg}$ of proteins) The results are represented by the mean \pm standard deviation. $\mathrm{P}$ $<0.001\left(*_{*}^{*}\right)=$ indicates a significant difference in the poisoned rats compared to controls. (\#\#\#) = indicates a significant difference in mercury-poisoned rats treated with the aqueous extract of $P$. at compared to mercury-poisoned rats. (\#) $=$ indicates a significant difference in the poisoned rats treated with the aqueous extract of $P$. at compared to the control rats $\mathrm{p}<0,01$ 


\subsection{Effect of treatment on LDH activities in cerebrum}

The increase in $\mathrm{LDH}$ level in brains poisoned by $\mathrm{HgCl}_{2}$ (349.51 $\pm 24.71 \mathrm{IU} / \mathrm{g})$ compared to the control and decrease by $\mathrm{HgCl}_{2}+P$. atlantica in brain when compared to those in $\mathrm{Hg}$ treated group. (Figure 3).

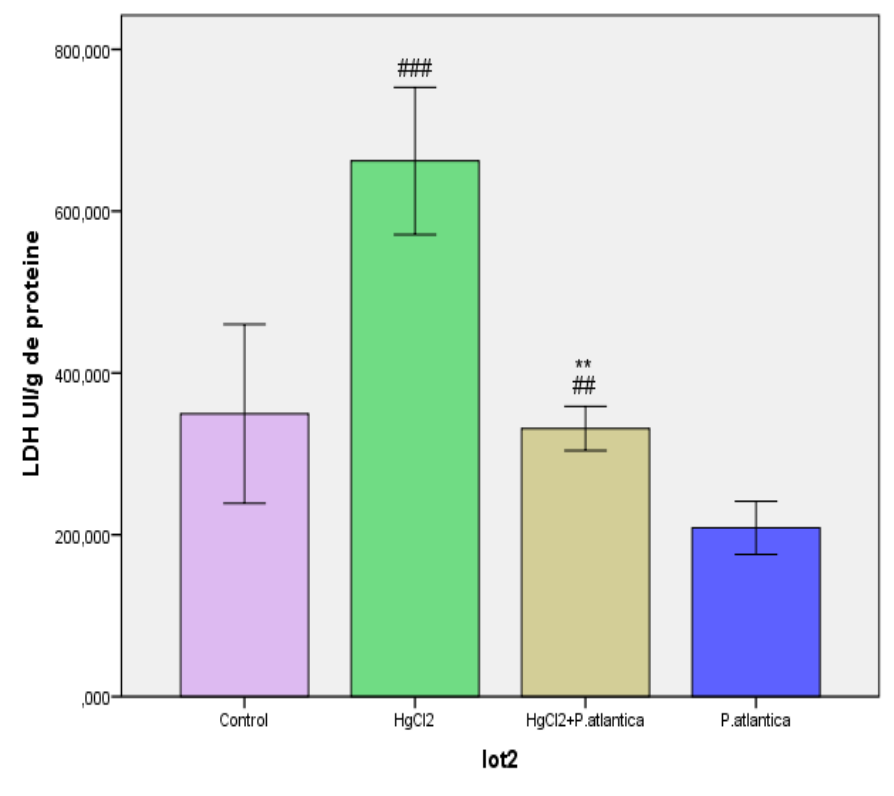

Barres d'erreur : Intervalle de confiance à $95 \%$

Figure 3: Effects of $P$. atlantica on LDH activity (U/g of proteins). The results are represented by the mean \pm standard deviation. $\mathrm{P}<0.001($ 粶) $=$ indicates a significant difference in the poisoned rats compared to controls. (\#\#\#) = indicates a significant difference in mercury-poisoned rats treated with the aqueous extract of $P$. at compared to mercury-poisoned rats. $(\#)=$ indicates a significant difference in the poisoned rats treated with the aqueous extract of $P$. at compared to the control rats $\mathrm{p}<0,01$

\subsection{Effect of treatment on AChE activity}

Administration of mercuric chloride to rats produced a significant $(\mathrm{P}<0.05)$ decrease in AChE brain activity of $(-$
76.51\%) compared to control rats. However, treatment with $\left(\mathrm{HgCl}_{2}+P\right.$. atlantica) $(150 \mathrm{mg} / \mathrm{kg})$ improved the increase of $\mathrm{AChE}$ compared to intoxicated rats. (Figure 4).

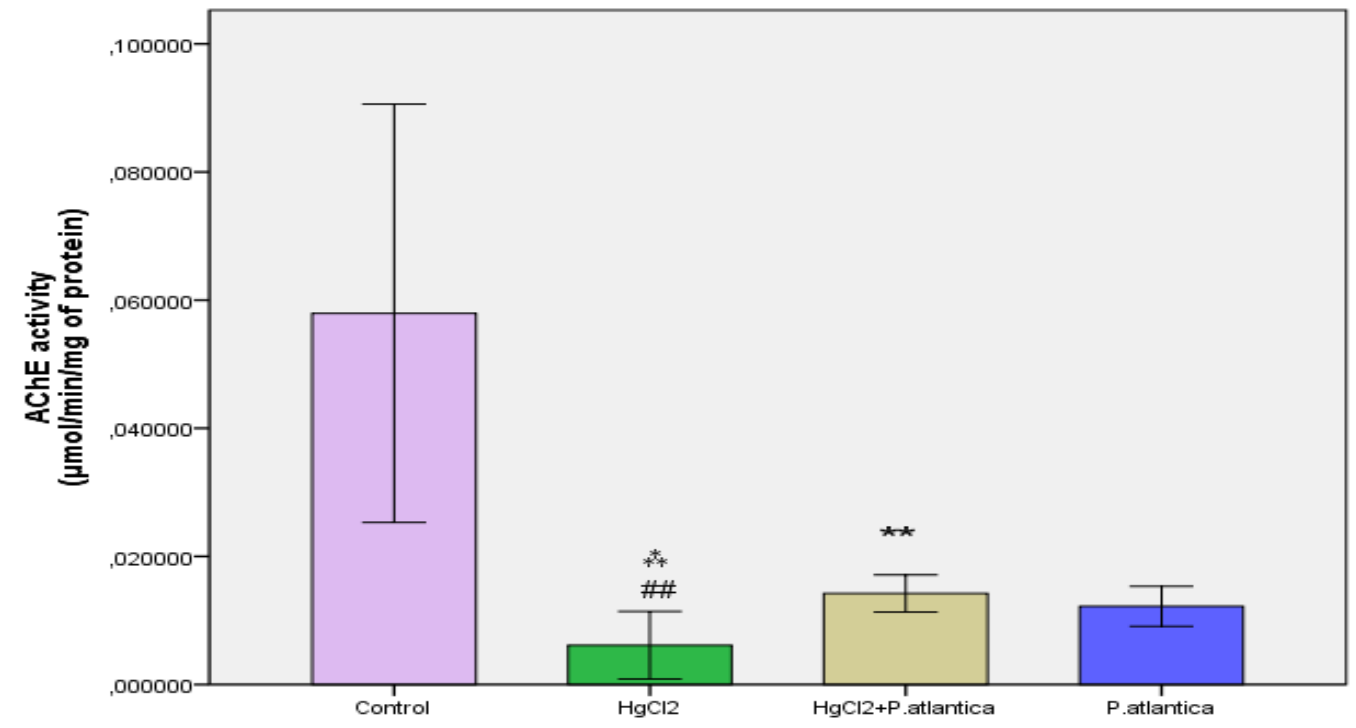

Figure 4: Effects of $P$. atlantica on AChE activity ( $\mu \mathrm{mol} / \mathrm{mn} / \mathrm{mg}$ of proteins). The results are represented by the mean \pm standard deviation. $\mathrm{P}<0.001$ (承) $=$ indicates a significant difference in the poisoned rats compared to controls. $(\# \# \#)=$ indicates a significant difference in mercury-poisoned rats treated with the aqueous extract of $P$. at compared to mercurypoisoned rats. $(\#)=$ indicates a significant difference in the poisoned rats treated with the aqueous extract of $P$. at compared to the control rats $\mathrm{p}<0,01$ 


\subsection{Effect of treatment on brain histopathological changes}

Pathological changes in the brain of rats intoxicated by $\mathrm{HgCl}_{2}$ degeneration neuronal necrosis, gliosis, fragmentation of myeline and axonal degeneration on cuts located intact in the control group. these changes were reduced to a minimum in the $+\mathrm{HgCl}_{2}+P$. atlantica (Figure 9).
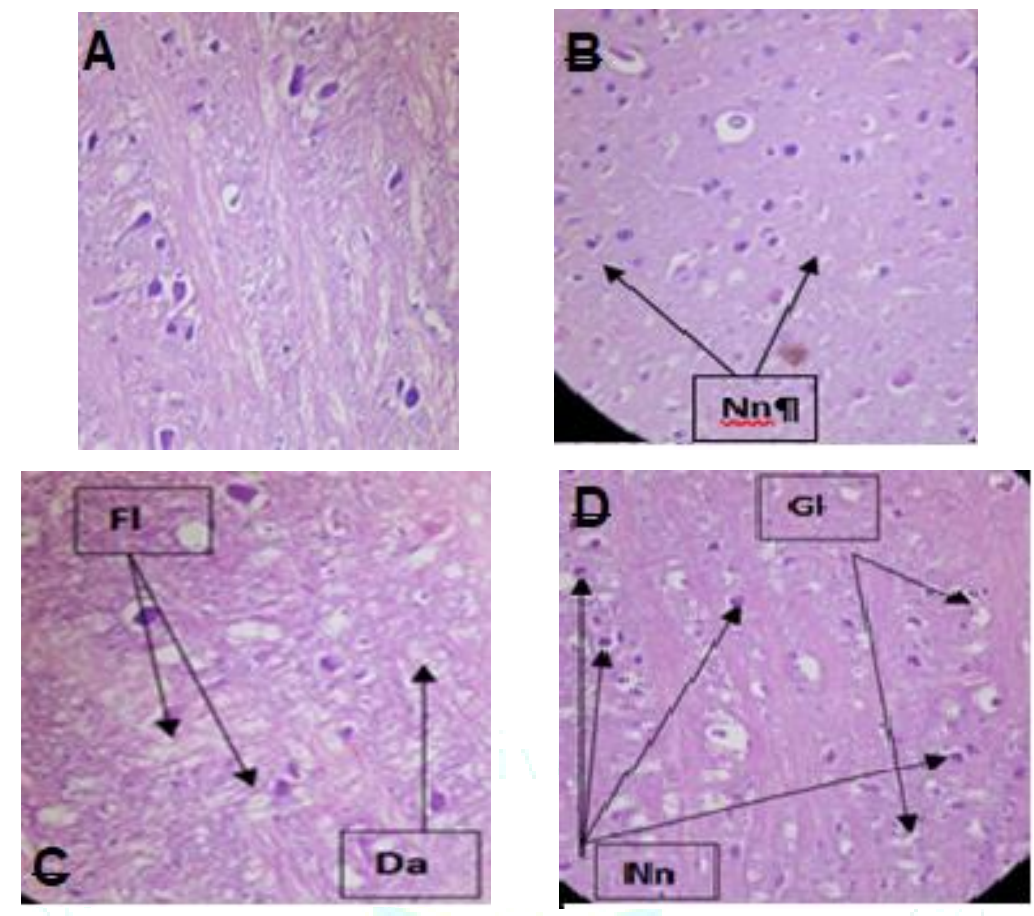

Figure 5: Effects of P. atlantica on $\mathrm{HgCl}$-induced histological changes in brain of control and experimental rats. A (control): section of cerebral (A) showing normal histo-architecture $(\mathrm{H} \& \mathrm{E}, 20 \times) ; \mathrm{B}(\mathrm{HgCl} 2+P$. atlantica:) showing very reduced neuronal necrosis ; C and D (HgCl2: 2.5mg/Kg Sections of cerebral showing neuronal necrosis gliosis, oedeme, fragmentation of myeline and axonal degeneration. Gl: gliose, Om : Oedeme, $\mathrm{Nn}$ : neuronale Necrosis, Fl: fragmentation of myeline, Da : axonal degeneration

\section{DISCUSSION}

Nerve cells and especially astrocytes are sensitive to damage caused by an excess of ROS such as $\mathrm{O}_{2}{ }^{\circ}, \mathrm{H}_{2} \mathrm{O}_{2}$, NO et $\mathrm{HO}^{\circ}$. These ROS responsible for cellular dysfunction, therefore for the disruption of nerve functions and the occurrence of neurodegenerative diseases ${ }^{21}$. The present results corroborate the previous results which demonstrated that exposure to mercury stimulated the generation of ROS. Our results agree with further studies ${ }^{22}$, 23. the combination of $\mathrm{Hg}$ and the P. atlantica extract in our study showed a reduction in TBARS levels in the brain. The GSH antioxidant system is an important target in mediating the neurotoxicity of mercury ${ }^{24}$. In this study, the administration of mercury led to the depletion of glutathione (GSH) content in the brain. From a molecular point of view, the decrease in GSH levels, which can occur following the formation of the GS-HgCH3 complex will lead to an increase in the generation of reactive species and oxidative damage in a plethora of biomolecules (acids nucleic acids, lipids and proteins) 25 . The evaluation of GSH levels in the brain tissue recorded a significant decrease in rats poisoned by $\mathrm{HgCl}_{2}$. Our result is in agreement with several studies 26, 27. The extract of $P$. atlantica administered in group 3 poisoned by $\mathrm{Hg}(\mathrm{Hg}+$ P. atlantica $)$ reveals an increase in the level of GSH comparing to the $\mathrm{HgCl}_{2}$. We have demonstrated a decrease in antioxidant enzymes (SOD, GPx, GST and catalase) in the brain intoxicated by mercury chloride $\mathrm{HgCl}_{2}$. The decrease in enzyme activity was a consequence of direct inhibitory effects, probably linked to Hg-selenol interactions $\mathbf{2 8 ,} \mathbf{2 2}$. Several researchers have approved the inhibitory and reducing effect of antioxidant enzymes during mercury chloride $\mathrm{HgCl}_{2}$ intoxication in the brain ${ }^{26}$. The significant increase in the level of glutathione-s transferase, catalase, superoxide dismutase and peroxidase in the brain treated with the extract of $P$. atlantica compared to the $\mathrm{HgCl}_{2}$ is carried out thanks to the presence of phenolic compounds in general and the flavonoids which could directly neutralize reactive oxygen metabolites due to the presence of different antioxidant substances. Our result agrees with work on burned rats receiving $300 \mu \mathrm{L} / \mathrm{kg} /$ day of $P$. atlantica oil for 14 days marked a significant increase in the levels of antioxidant enzymes SOD, GPX, and VEGF (Vascular Endothelial Growth Factor) ${ }^{29}$. AChE is a complex protein that has an active center, It belongs to the family of hydrolases and it is expressed in the central nervous system and muscles, its role is to hydrolyze the neurotransmitter acetylcholine in order to complete the transmission of the nerve impulse and thus restore the excitability of the cholinergic synapses ${ }^{30}$. The administration of $\mathrm{HgCl}_{2}$ leads to a reduction in acetylcholine esterase levels in the brain of the rats of the second group compared to the rats of the first group controls. which confirms the study of Dahalan and al.,31. It was found that all the metal ions that $\mathrm{Ag} 2+, \mathrm{Cd} 2+, \mathrm{Cu} 2+$ $\mathrm{Hg} 2+\mathrm{Pb} 2+$ and Zn2 + significantly inhibited the activity of AChE but with different percentages of inhibition. Inhibition of acetylcholine esterase activity in the brain treated with $P$. atlantica $\left(\mathrm{HgCl}_{2}+\right.$ P. atlantica) comparing to the addict what is consistent with the work of Nadeem et al.,32. $P$. atlantica is mainly characterized by monoterpenoids such as $\alpha$-pinene which have AChE 
inhibitory and antioxidant activities. In addition, previous studies have shown that limonene is a potent inhibitor of AChE as well as $\beta$-phellandrene ${ }^{33}$.

As a result, lactate dehydrogenase (LDH) is a cytosolic enzyme, which will be released and its activity is measured in order to assess cell death, in particular primary necrosis and secondary necrosis (necrosis following apoptosis ). The increase in LDH level in brains poisoned by $\mathrm{HgCl}_{2}$ (349.51 $\pm 24.71 \mathrm{IU} / \mathrm{g}$ ) compared to the control, which confirms studies showing a high LDH level in the brain tissue ${ }^{34}$. From the observation of the histological sections at the level of the cerebral parenchyma that we carried out reveals that the toxicity of mercury was manifested by unequivocal tissue damage. Neurodegenerations have been characterized by morphological changes such as neuronal loss and vacuolation ${ }^{35}$ these neurodegenerative changes in the brain could invariably affect the learning, memory and hearing capacities associated with its functions. Our results also agree with Akintunde and Babaita35. The protective effect against brain bonds induced by mercury was approved by the Pistacia extract which reduced neuronal necrosis and prevented other pathologies such as gliosis degenerate axon which is consistent with the work of Liu et al.,36, This reduction in ROS is due to secondary metabolites such as: flavonoids and tannins which is found in the extracts of the leaves of $P$. atlantica.

In conclusion, the results of the present study indicate that $P$. atlantica demonstrated significantly higher levels of rescue of $\mathrm{HgCl}_{2}$-induced neurotoxicity and oxidative damage, histopathological changes and inhibition of AChE.

\section{Acknowledgments}

This research was supported by the Algerian Ministry of Higher Education and Scientific Research and DGRSDT

\section{Conflict of interest statement}

The authors report no conflict of interest.

\section{REFERENCES}

1. Officioso, A., Panzella, L., Tortora, F., Alfieri, M. L., Napolitano, A., \& Manna, C. (2018). Comparative analysis of the effects of olive oil hydroxytyrosol and its 5-S-lipoyl conjugate in protecting human erythrocytes from mercury toxicity. Oxid Med Cell Longev., 2018; 2018:9042192.

2. Caglayan C., Kandemir FM., Yildirim S., Kucukler S., Eser G. Rutin protects mercuric chloride-induced nephrotoxicity via targeting of aquaporin 1 level, oxidative stress, apoptosis and inflammation in rats.; J Trace Elem Med Biol. 2019; 54:69-78.

3. Esdaile, L. J., \& Chalker, J. M.. The Mercury Problem in Artisanal and Small-Scale Gold Mining. Chem. Eur. J. 2018; 24(27):69056916.

4. Chan, Thomas YK. Inorganic mercury poisoning associated with skin-lightening cosmetic products. Clinical toxicology. 2011; 49(10):886-891.

5. Copan, L., Fowles, J., Barreau, T., \& McGee, N. Mercury toxicity and contamination of households from the use of skin creams adulterated with mercurous chloride (Calomel). Int J Env Res Pub He., 2015; 12(9):10943-10954

6. Abu-Taweel, G. M. Neurobehavioral protective properties of curcumin against the mercury chloride treated mice offspring. Saudi J. Biol. Sci., 2019; 26(4): 736-743.

7. Koli, S., Prakash, A., Choudhury, S., Mandil, R., \& Garg, S. K. Mercury affects uterine myogenic activity even without producing any apparent toxicity in rats: Involvement of calcium-signaling cascades. J Trace Elem Med Bio., 2020; 57: 047.

8. Corrêa, M. G., Bittencourt, L. O., Nascimento, P. C., Ferreira, R. O., Aragão, W. A. B., Silva, M. C. F., \& Crespo-Lopez, M. E. Spinal cord neurodegeneration after inorganic mercury long-term exposure in adult rats: Ultrastructural, proteomic and biochemical damages associated with reduced neuronal density. Ecotox Environ Safe., 2020; 191:110-159.

9. Xu, J., Zhang, J., Lv, Y., Xu, K., Lu, S., Liu, X., \& Yang, Y.. Effect of soil mercury pollution on ginger (Zingiber officinale Roscoe): Growth, product quality, health risks and silicon mitigation. Ecotox Environ Safe., 2020; 195:110472.

10. Barghout N, Chebata N, Moumene S, Khennouf S, Gharbi A, Gharbi A, El Hadi D, Antioxidant and antimicrobial effect of alkaloid bulbs extract of Polianthes tuberosa $\mathrm{L}$. (Amaryllidaceae) cultivated in Algeria, Journal of Drug Delivery and Therapeutics 2020; 10(4):44-48

11. Ben Ahmed, Z., Yousfi, M., Viaene, J., Dejaegher, B., Demeyer, K., Mangelings, D., \& Vander Heyden, Y.. Seasonal, gender and regional variations in total phenolic, flavonoid, and condensed tannins contents and in antioxidant properties from Pistacia atlantica ssp. leaves. Pharm. Biol., 2017; 55(1):1185-1194.

12. Hasheminya, S. M., \& Dehghannya, J. Composition, phenolic content, antioxidant and antimicrobial activity of Pistacia atlantica subsp. kurdica hulls' essential oil. Food Bioscience. 2020; 34:100510.

13. Bagheri, M., Mostafavinia, A., Abdollahifar, M. A., Amini, A., Ghoreishi, S. K., Chien, S., \& Bayat, M.. Combined effects of metformin and photobiomodulation improve the proliferation phase of wound healing in type 2 diabetic rats. Biomedicine \& Pharmacotherapy, 2020; 123:109776.

14. Ohkawa, H., Ohishi, N., \& Yagi, K.. Assay for lipid peroxides in animal tissues by thiobarbituric acid reaction. Anal. Biochem., 1979; 95(2):351-358.

15. Sedlak, J., \& Lindsay, R. H.. Estimation of total, protein-bound, and nonprotein sulfhydryl groups in tissue with Ellman's reagent. Anal. Biochem., 1968; 25:192-205.

16. Aebi H. Catalase. In: Berg Meyer H., editor. Methods of enzymatic analysis. 2nd ed. Weinheim: Verlag Chemie. 1974; p. 673-84

17. Rotruck, J. T., Pope, A. L., Ganther, H. E., Swanson, A. B., Hafeman, D. G., \& Hoekstra, W. G., Selenium. Biochemical Role as a Component of Glutathione Peroxidase. Science, 1973; 179:588-590.

18. Marklund, S., \& Marklund, G. A simple assay for superoxide dismutase using auto oxidation of pyrogallol. Eur J Biochem., 1974; 47:469-72.

19. Ellman, G. L., Courtney, K. D., Andres Jr, V., \& Featherstone, R. M. A new and rapid colorimetric determination of acetylcholinesterase activity. Biochemical pharmacology, 1961; 7(2): 88-95.

20. Lowry $\mathrm{OH}$, Rosebrough NJ, Farr AL, Randall RJ. Protein measurement with the Folin phenol reagent. J Biol Chem. 1951; 193(1):265-75

21. Lzurie S., Timothy J. Oxidative damage to macromolecules in human Parkinson disease and the rotenone model. Free Radical Bio Med., 2013; 62:111-120.

22. Malqui H., Anarghou H., Ouardi F., Ouasmi N., Najimi M., Chigr F. Continuous Exposure to Inorganic Mercury Affects Neurobehavioral and Physiological Parameters in Mice. J Mol Neurosci., 2018; 66(2):291-305.

23. Sudo K., Van Dao C., Miyamoto A., Shiraishi M. Comparative. analysis of in vitro neurotoxicity of methylmercury, mercury, cadmium, and hydrogen peroxide on SH-SY5Y cells. J Vet Med Sci., 2019; 6:828-837.

24. Stringari J., Nunes A., Franco L., Bohrer D., Garcia S., Dafre L., Farina M. Prenatal methylmercury exposure hampers glutathione antioxidant system ontogenesis and causes longlasting oxidative stress in the mouse brain. Toxicol Appl Pharm., 2008; 227:147-154.

25. Zalups RK, Bridges CC. Mechanisms involved in the renal handling and toxicity of mercury. Comprehensive toxicology. 2018; 10:410-435

26. Bubber, P. A Study on Prooxidative and Neurotoxic Effects of Mercury Chloride in Rats. EC Pharmacology and Toxicology., 2019; 7:112-124.

27. Moneim, A. E. A. The neuroprotective effect of berberine in mercury-induced neurotoxicity in rats. Metab Brain Dis., 2015; 30(4):935-942.

28. Zefferino R, Piccoli C, Ricciardi N, Scrima R, Capitanio N. Possible Mechanisms of Mercury Toxicity and Cancer Promotion: Involvement of Gap Junction Intercellular Communications and Inflammatory Cytokines. Oxid Med Cell Longev., 2017; 2017:702858 
29. Shahouzehi, B., Sepehri, G., Sadeghiyan, S., \& MasoomiArdakani, Y. Effect of Pistacia atlantica resin oil on antioxidant, hydroxyprolin and VEGF changes in experimentallyinduced skin burn in rat. World J. Plast. Surg., 2018; 7(3):357.

30. Gendrel, M., Atlas, E. G., \& Hobert, O.. A cellular and regulatory map of the GABAergic nervous system of C. elegans. Elife, 2016; 5:e17686.

31. Dahalan A., Khalid K., Khalil M., Shukor Y., Syed N., Shamaan A.. Characterisation of cholinesterase from kidney tissue of Asian seabass (Lates calcarifer) and its inhibition in presence of metal ions J. Environ. Biol., 2017; 38:383-388

32. Nadeem S., Kabouche A., Kabouche Z. .Essential Oils Composition, Anticholinesterase and Antioxidant Activities of Pistacia atlantica Desf. Rec. Nat. Prod., 2017; 11:411-41.

33. Zerrad K., Benhamouda A., Chaib I., Larrif A., Mediouni J. Chemical composition, fumigant and anti-acetylcholinesterase activity of the Tunisian Citrus aurantium L.essential oils. Ind. Corps Prod., 2015; 76:121-127.

34. Agarwal R., Goel K., Chandra R., Behari R. Role of vitamin E in preventing acute mercury toxicity in rat. Environ toxicol phar., 2010; 29:70-78.

35. Akintunde, J. K., \& Babaita, A. K. Effect of PUFAs from Pteleopsis suberosa stem bark on androgenic enzymes, cellular ATP and prostatic acid phosphatase in mercury chloride-exposed rat. Middle East Fertil. Soc., 2017; 22(3):211-218.

36. Liu C., Peng J., Zhang L., Wang S., Ju S., Liu C. Mercury adsorption from aqueous solution by regenerated activated carbon produced from depleted mercury-containing catalyst by microwave-assisted decontamination. J. Clean. Prod., 2018; 196:109-121. 